\title{
Inlet Pressure Effects on Subatmospheric Flame Stabilization with an Optimum Size of a Cavity-Based Combustor
}

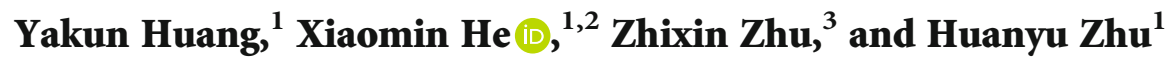 \\ ${ }^{1}$ Jiangsu Province Key Laboratory of Aerospace Power System, College of Energy and Power Engineering, Nanjing University of \\ Aeronautics and Astronautics, Nanjing 210016, China \\ ${ }^{2}$ Co-Innovation Center for Advanced Aero-Engine, Beijing 100191, China \\ ${ }^{3}$ Zhejiang Key Laboratory of Health Intelligence Kitchen System Integration, Ningbo, China
}

Correspondence should be addressed to Xiaomin He; hxm@nuaa.edu.cn

Received 7 December 2019; Accepted 16 April 2020; Published 30 June 2020

Academic Editor: Linda L. Vahala

Copyright (c) 2020 Yakun Huang et al. This is an open access article distributed under the Creative Commons Attribution License, which permits unrestricted use, distribution, and reproduction in any medium, provided the original work is properly cited.

Experimental studies are conducted to find an optimum size of the cavity flameholder, which is a new combustion concept of a turbine-based combined-cycle (TBCC) engine with an excellent flame stabilization. Besides, the effect of inlet pressure on the subatmospheric performance is investigated. The experimental results indicate that the increase of the cavity length improves the flame stability with an enlarged fuel/air mixture residence time, which suggests that the big length-height ratio in a proper range of the cavity with a stable dual-vortex should be chosen when designing the cavity-based combustor. In addition, the decrease in lean ignition and the lean blowout equivalence ratios can be attributed by either increase in the inlet pressure and temperature or decrease in the Mach number. The increase in inlet pressure will lead to a linear decrease in the lean blowout equivalence ratio with a slope of 0.66 per $0.1 \mathrm{MPa}$, whereas the lean ignition equivalence ratio has a rapid drop with the increase of pressure from $0.06 \mathrm{MPa}$ to $0.08 \mathrm{MPa}$ and reduces slowly with the growth of pressure in the range of $0.08 \mathrm{MPa}$ to $0.1 \mathrm{MPa}$. The detailed analysis of the flow field indicates that the characteristic time-scale theory can ideally explain and predict the change of flame stability in the trapped vortex cavity.

\section{Introduction}

As a novel flameholder, the trapped vortex flame-stabilizing device is rarely investigated under a low pressure operating condition, which has a wider operating range than the conventional combustor flameholder, where there is a poor investigation as well. However, the efficient and reliable ignition and reignition, especially in high altitude conditions with thin oxygen and low temperature, are indispensable for the turbine-based combined-cycle (TBCC) engine augmentor [1]. It is widely acknowledged that the air temperature and pressure will drop by $0.6 \mathrm{~K}$ and $0.786 \mathrm{kPa}$ when the altitude increases by $100 \mathrm{~m}$. A NASA report shows that the combustion pulsation with the harsh noise will happen and results in very close limits of a lean blowout (LBO) and rich blowout if the altitude is higher than $6 \mathrm{~km}$ where the ambient pressure less than $0.047 \mathrm{MPa}$ [2]. As a consequence, it is necessary to exploit the combustion performance of a promising flame-stabilizing device.

Traditionally, the flame stabilization in afterburner and ramjet combustors is achieved by the recirculation zone behind a bluff body, which is highly associated with inlet conditions [3, 4]. Different from the conventional flamestabilizing mechanism of the bluff body, the ignition and flame stabilization are conducted in the located vortex which is trapped by the geometry of the cavity. As an advanced concept flameholder, the trapped vortex creates a recirculation zone with upstream fuel injection, in which the fresh fuel/air mixture is continuously ignited by hot combustion products. Besides, the cavity can effectively weaken the disturbance of the inlet parameters of the augmentor and expand the operating range, which is $40 \%$ wider than that of conventional gas turbine combustor [5, 6]. Substantial investigations of the trapped vortex combustor (TVC) have been conducted on 
aeroengine flame stabilization since the TVC concept was proposed in the 1990s [7-10]. Besides, the cavity surrounding the casing with serval struts radially hanging on the fore-wall can reduce the equivalence ratio $(\varphi)$ of the lean blowout (LBO) and improve the combustion efficiency $(\eta)$ [11-13]. Additionally, the dual-vortex, where the fuel is ideally injected from the injector installing above the centerline of the fore-wall, will be "safely locked" and fully filled inside the cavity if the cavity designed with the proper size [14], to provide effective flame stabilization $[10,15]$. Besides, the secondary vortex protects the main vortex from being destroyed by the main flow, which can implement higher combustion efficiency and the lower LBO limits $(\sim 50 \%)$ than that in a conventional combustor $[16,17]$.

The benefit of a cavity-based combustor has already been confirmed by extensive research in aeroengines, ramjets, and scramjets [18-20]. There is no doubt that the trapped vortex cavity has excellent flame stabilization ability, which effectively reduces pollutant emission [21, 22]. Whereas, most research focuses on characteristics of the flow field in the cavity [23, 24], fuel-air mixing [25], and combustion efficiency [26] at atmospheric pressure, while the high altitude status occupies the most part of operating range of the ramjet engine. Therefore, due to the absence of flame stabilization characteristics of TVC in high altitude status, the effect of inlet pressure on lean ignition and lean blowout limits need to be fully understood. Furthermore, in order to provide researchers with an efficient combustor at low pressure, it is necessary to explore the optimal size of the cavity.

\section{Combustor and Experimental Setup}

2.1. Combustor Model. Figure 1 shows 2-D schematics and the photograph of the augmentor with a cavity and a radial $\mathrm{V}$-gutter flame, where the center section is drawn in a rectangle augmentor with a size of $120 \times 144 \times 1360 \mathrm{~mm}$. As shown, the augmentor is composed of a diffuser with the real variable area bypass injector (RVABI), a cavity, an airassisted multipoint injector (AMI), a V-gutter flameholder, a spark plug, and two inlets, which are the core stream inlet and bypass stream inlet ${ }_{2}$, respectively. The ratio of the diffuser is 1.38. The RVABI, which is designed for the modal conversion between the turbofan afterburner and ramjet, has adjustable blades in front of the augmentor. In this paper, the TBCC is operating at a ramjet-operating mode. Additionally, the superior design of the annular cavity with a radial $\mathrm{V}$ gutter flameholder has already been proven by previous numerical simulations and combustion tests [27]. Meanwhile, previous researches $[21,28]$ show that the AMI matches well with the cavity combustion. The RP-3 liquid fuel is injected vertically onto the splash plate by a plain orifice with a diameter of $0.5 \mathrm{~mm}$. The diameter of the multihole tube is $10 \mathrm{~mm}$, in which the evaporating tube has 20 holes with a $2 \mathrm{~mm}$ diameter with a pitch of $5.7 \mathrm{~mm}$.

The 2-D schematic of the cavity and AMI is depicted in Figure 1 (c), with a distance of $20 \mathrm{~mm}$ from the center. Three types of cavity composed of the dual-vortex are designed, with $L=41.5 \mathrm{~mm}, L=46.5 \mathrm{~mm}$, and $L=51.5 \mathrm{~mm}$, respectively. The depth of the fore-wall is $40 \mathrm{~mm}$ and the after- wall is $29.5 \mathrm{~mm}$. Besides, the widths of the cavity air slot and the driving air slot are both $1.6 \mathrm{~mm}$ in the cavity forewall and after-wall. Furthermore, the air flows through two slots with a height difference that will form a dual-vortex structure in the cavity. The cavity is fully filled with the main vortex, and the secondary vortex appears in the corner of the fore-wall meeting the mainstream. Therefore, the secondary vortex will separate the main vortex from the mainstream, protecting the stability of the main vortex and exchanging energy and composition. However, the double vortex structure is affected when the fluid in the cavity is attracted by the low-pressure area behind the radial V-gutter flameholder at the central section (shown in Figure 1(a)). A noteworthy feature of the fore-wall is that little-air mixed with fuel will enter into the cavity from AMI and flows into the main vortex, completing ignition to establish a stable flame zone, which can ignite the whole combustor. Besides, the flame spread out from the spark plug with $12 \mathrm{~J}(8 \mathrm{~Hz})$ installed at the center of the bottom-wall with a $z$-axis distance of $20 \mathrm{~mm}$ to the center section. Furthermore, a successful ignition is marked by the observation, through an optical quartz glass, that the steady flame fills the entire cavity.

2.2. Experimental System. Experimental studies are conducted in a sector channel with an air supply and exhaust system, which is schematically shown in Figure 2. The experimental system is divided into four parts: air supply device, fuel supply system, heater, and the test section. The air supply device can provide the dried air with a maximum pressure of $0.8 \mathrm{MPa}$ and a maximum total rate of $1.5 \mathrm{~kg} / \mathrm{s}$. The incoming air is divided into two streams, one electrically heated and the other preheated by combustion with RP-3 liquid fuel. The electric heater can raise the airflow temperature by $200 \mathrm{~K}$, while the preburner can heat the room temperature air up to a maximum of $873 \mathrm{~K}$. Besides, an orifice flowmeter with an accuracy of $0.75 \%$ is used to measure the total airflow. The pressure and temperature at the inlet are measured by the pressure gauge and the K-type thermocouple, which are both mounted $50 \mathrm{~mm}$ upstream from the test section. The uncertainties of the K-type thermocouple and pressure gauge are both $0.4 \%$. Also, the unvitiated air from the electrical heater and the vitiated air from preburner are supplied to the core inlet and the bypass inlet of the test rig, respectively. The fuel is pressurized by the bump into the experimental model, and the flow rate is determined by the pressure gauge. Furthermore, the relationship between the fuel flow rate and pressure drop is calibrated before the test. The uncertainties of the pressure gauges and the electronic scale are $0.4 \%$ and $0.005 \%$, respectively. Then, the correlation is supplied as follows:

$$
\Delta P_{\text {fuel }}=0.1249 \mathrm{~m}_{\text {fuel }}{ }^{1.9665}
$$

The combustor has two inlets: core inlet and bypass inlet, which are denoted by subscripts 1 and 2, respectively. For the present experiment, the effect of cavity length and inlet pressure on ignition and blowout performance is mainly studied, which is directly related to the flame stability of the cavity. Therefore, the parameters of the core inlet are kept the same, 


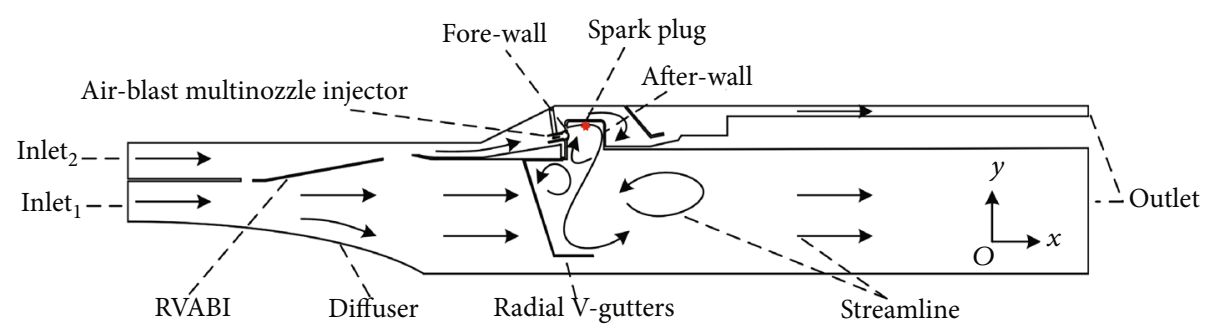

(a)

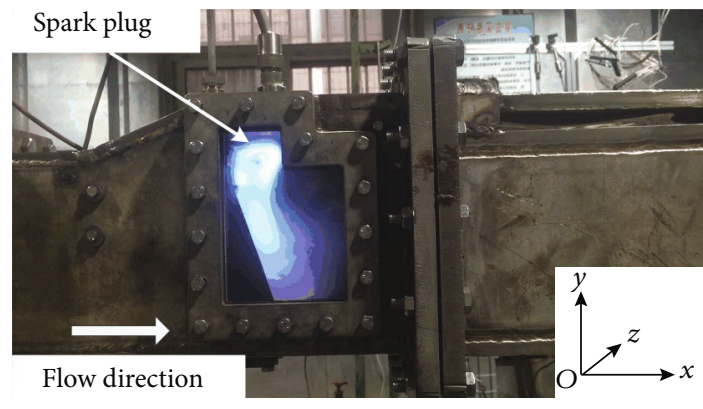

(b)

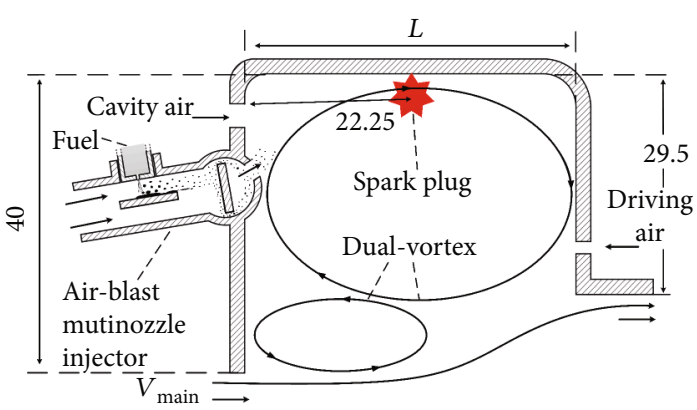

(c)

Figure 1: A 2-D schematic and a photograph of augmentor at the center section: (a) schematic of the augmentor, (b) a photograph of augmentor, and (c) schematic of the injector and the position of spark plug at a $20 \mathrm{~mm}$ section far from the center section. All dimensions in $\mathrm{mm}$.

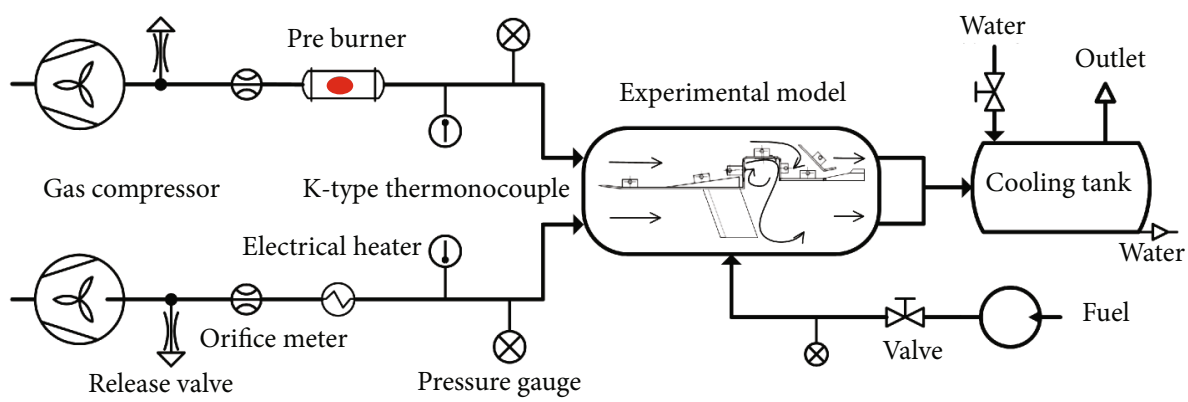

Figure 2: Experimental setups for combustion.

while the parameters of bypass inlet change within a certain range. The detailed operational parameters for the combustor are listed in Table 1.

\section{Results and Discussion}

3.1. Combustion Test Results. Two different experimental approaches are adopted in the investigation on the performance of flame stabilization to determine the optimum size and limits of the cavity for ignition and lean blowout under the low-pressure condition. The performance is quantified by the equivalence ratios of ignition and lean blowout. The equivalence ratio corresponding to the lowest fuel pressure drop with the steady flame is regarded as the lean ignition equivalence ratio [15]. Besides, the lean blowout equivalence ratio corresponds to the lowest fuel/air ratio at which point the flame disappears due to deceased fuel mass flow and cannot be reignited when increasing the fuel mass flow.
TABLE 1: Summary of experimental conditions.

\begin{tabular}{cccccc}
\hline$M a_{1}$ & $T_{1}, \mathrm{~K}$ & $M a_{2}$ & $T_{2}, \mathrm{~K}$ & $L, \mathrm{~mm}$ & $P, \mathrm{MPa}$ \\
\hline 0.18 & 473 & $0.30-0.60$ & $343-673$ & $41.5-51.5$ & $0.06-0.10$ \\
\hline
\end{tabular}

3.1.1. The Effect on the Cavity Length. Three different sizes of the cavity are designed to investigate the effect of cavity length on the lean ignition and blowout performance of a cavity pilot augmentor. The performance of the flame stabilization was evaluated by the lean ignition and lean blowout equivalence ratios, shown in Figures 3 and 4 . At $T_{2}=343 \mathrm{~K}$, the lean ignition equivalence ratio is proportional to the Mach number, while at $T_{2}=573 \mathrm{~K}$, it is inversely proportional to $M a$. The tendencies of the lean ignition equivalence ratios at $T_{2}=343 \mathrm{~K}$ continued to decrease with the Mach number increasing, while the lean ignition equivalence ratios at $T_{2}=573 \mathrm{~K}$ increase with the increase of $M a$. The minimum lean ignition equivalence ratio of 0.679 is achieved at 


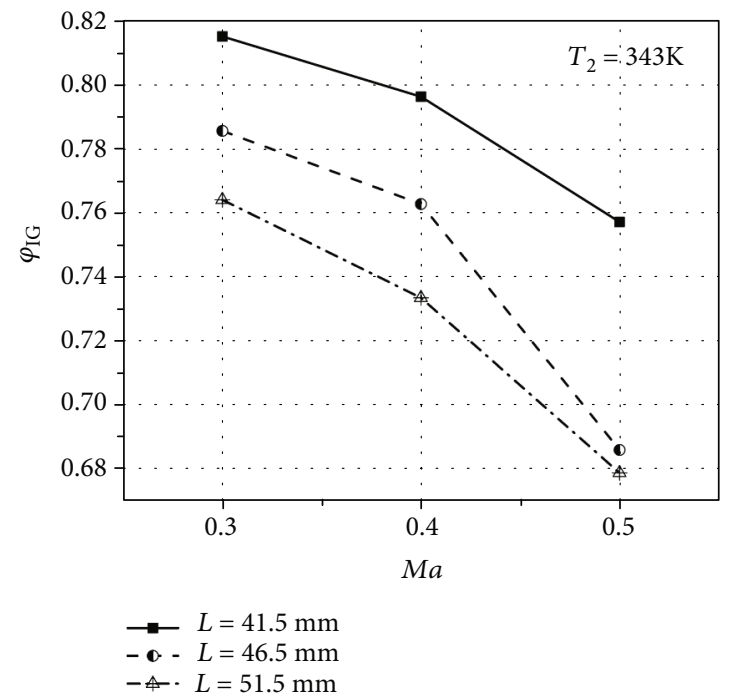

(a)

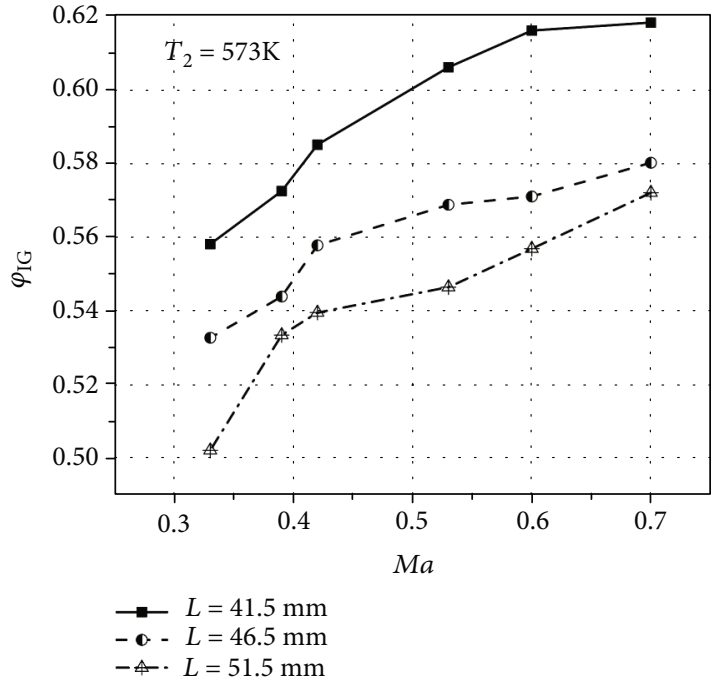

(b)

FIgURE 3: Lean ignition equivalence ratios of combustor with different lengths of cavity: (a) $T_{2}=343 \mathrm{~K}$, (b) $T_{2}=573 \mathrm{~K}$.

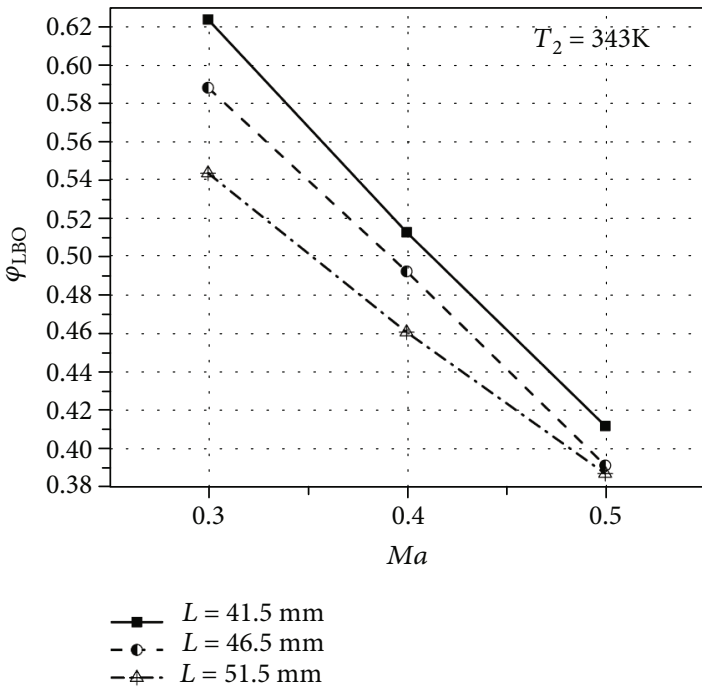

(a)

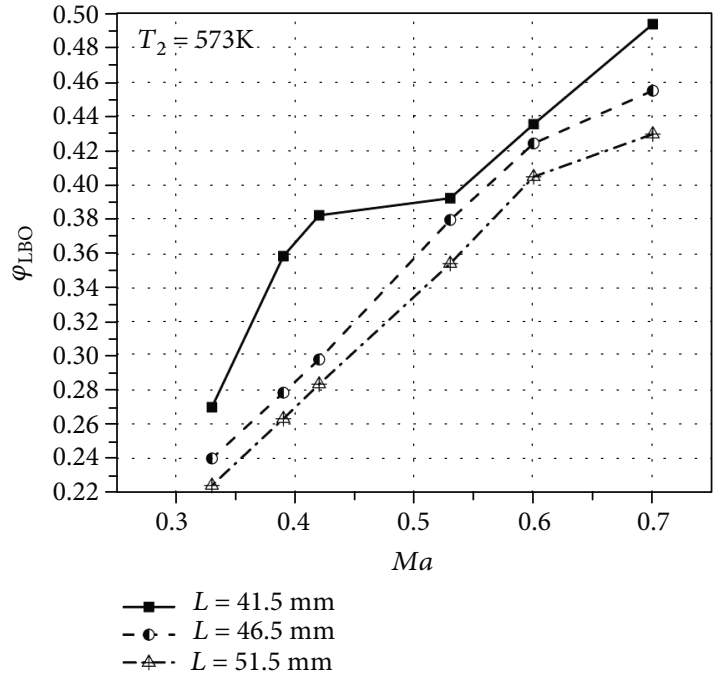

(b)

Figure 4: Lean blowout equivalence ratios of combustor with different lengths of cavity: (a) $T_{2}=343 \mathrm{~K}$, (b) $T_{2}=573 \mathrm{~K}$.

$M a_{2}=0.5$ and $T_{2}=343 \mathrm{~K}$ with a cavity length of $51.5 \mathrm{~mm}$. It is $1.02 \%$ and $10.30 \%$ smaller than that with a cavity length of $L=46.5 \mathrm{~mm}$ and $L=41.5 \mathrm{~mm}$, respectively, under the same Mach number and temperature, whereas the minimum equivalence ratio which happens at $M a_{2}=0.33$ in $T_{2}=573 \mathrm{~K}$ is 0.502 , which is $5.82 \%$ and $10.03 \%$ smaller than that in $L=46.5 \mathrm{~mm}$ and $L=41.5 \mathrm{~mm}$. To achieve a stable flame, the Mach number cannot exceed 0.5 at the temperature of $343 \mathrm{~K}$. This limit increases to 0.7 with a higher temperature of $573 \mathrm{~K}$. The LBO equivalence ratios under different cavity lengths and temperature are plotted in Figure 4. Similar observations can be made where the minimum LBO equivalence ratio occurs at the longest cavity length, while the maximum ratio of ignition occurs at the shortest length. This phenomenon indicates that the longer length of the cavity is more beneficial to reduce the equivalence ratio. Similarly, the increase of the Mach number will lead to an increase of the LBO equivalence ratio in $T_{2}=343 \mathrm{~K}$, which will lead to a drop of the LBO equivalence ratio in $T_{2}=573 \mathrm{~K}$. Besides, the $\mathrm{LBO}$ equivalence ratio in $T_{2}=343 \mathrm{~K}$ has a linear decrease with the increase of the inlet Mach number, where the average equivalence ratio of LBO at $M a_{2}=0.3$ is 0.788 , which is $10.19 \%$ bigger than that at $M a_{2}=0.5$. At the same time, the average equivalence 
ratio of $\mathrm{LBO}$ in $L=51.5 \mathrm{~mm}$ at $M a_{2}=0.3$ and $T_{2}=343 \mathrm{~K}$ is 0.725 , which is $2.60 \%$ and $8.13 \%$ larger than that in $L=$ $46.5 \mathrm{~mm}$ and $L=41.5 \mathrm{~mm}$. It is obvious that the flame stability corresponding to $L=51.5 \mathrm{~mm}$ is slightly larger than that in $L=46.5 \mathrm{~mm}$ and is greatly better than that in $L=$ $41.5 \mathrm{~mm}$. For example, the worst performance of LBO in $T_{2}=573 \mathrm{~K}$ appears at $M a_{2}=0.5$ and $L=41.5 \mathrm{~mm}$, in which the equivalence ratio is $6.15 \%$ and $7.47 \%$ larger than that in $L=46.5 \mathrm{~mm}$ and $L=51.5 \mathrm{~mm}$, respectively. The similar curves appear in $T_{2}=343 \mathrm{~K}$ and $T_{2}=573 \mathrm{~K}$ with a rule that the longest of the cavity length has the lowest equivalence ratio, which is strong evidence that the growth of the cavity length improves the flame stability.

3.1.2. The Effect on the Inlet Pressure. Three different values of pressure are designed to investigate the effect of inlet pressure on the lean ignition and blowout performance of a cavity pilot augmentor. Figures 5 and 6 portray the equivalence ratios of the lean ignition and lean blowout of the combustor. Immediately apparent from Figure 5 is the $\varphi_{\mathrm{IG}}$ and $\varphi_{\mathrm{LBO}}$ of various inlet temperatures. Four profiles with the same trend corresponding to $T_{2}=343 \mathrm{~K}, 473 \mathrm{~K}, 573 \mathrm{~K}$, and $673 \mathrm{~K}$ are excellent and demonstrate that the $\varphi_{\mathrm{IG}}$ and $\varphi_{\mathrm{LBO}}$ decrease with the increase of pressure. It is noteworthy that the smallest tendency to the decrease of $\varphi_{\mathrm{IG}}$ corresponding to $T_{2}=$ $473 \mathrm{~K}$ is caused by the growth of the pressure at the inlet from $0.06 \mathrm{MPa}$ to $0.1 \mathrm{MPa}$. Besides, the average values of $\varphi_{\mathrm{IG}}$ obtained at $T_{2}=343 \mathrm{~K}$ and $573 \mathrm{~K}$ are $27.3 \%$ and $22.3 \%$ larger than that at $T_{2}=673 \mathrm{~K}$. Meanwhile, the average $\varphi_{\mathrm{LBO}}$ at $T_{2}=$ $673 \mathrm{~K}$ is about 0.42 , which is $4.5 \%, 12.4 \%$, and $29.3 \%$ smaller than that at $T_{2}=573 \mathrm{~K}, 473 \mathrm{~K}$, and $343 \mathrm{~K}$, respectively. There is no doubt that the maximum value of $\varphi_{\mathrm{IG}}$ and $\varphi_{\mathrm{LBO}}$ appears at $0.06 \mathrm{MPa}$ and $343 \mathrm{~K}$, which are 0.82 and 0.67 , respectively.

Figure 6 shows the $\varphi_{\mathrm{IG}}$ and $\varphi_{\mathrm{LBO}}$ of four $M a$ numbers at $T_{2}=573 \mathrm{~K}$. It is clear that the maximum $\varphi_{\text {IG }}$ of about 0.73 occurs at $M a_{2}=0.6$, which is $18.1 \%, 13.1 \%$, and $10.1 \%$ larger than that in $M a_{2}=0.3,0.4$, and 0.5 , respectively. Furthermore, the minimum $\varphi_{\text {IG }}$ of 0.50 appears at $M a_{2}=0.3$, which is $5.9 \%, 8.1 \%$, and $9.8 \%$ smaller than that in $M a_{2}=0.4,0.5$, and 0.6 , respectively. Besides, the $\varphi_{\mathrm{IG}}$ has a rapidly drop with the increase of pressure from $0.06 \mathrm{MPa}$ to $0.08 \mathrm{MPa}$ and reduces slowly with the growth of pressure in the range of $0.08 \mathrm{MPa}$ to $0.1 \mathrm{MPa}$. Moreover, the $\varphi_{\mathrm{IG}}$ corresponding to $M a_{2}=0.3$ decreases by $20.1 \%$ and $23.0 \%$ as the pressure changes increasingly from $0.6 \mathrm{MPa}$ to $0.8 \mathrm{MPa}$ and $0.1 \mathrm{MPa}$. In addition, the $\varphi_{\mathrm{LBO}}$ linearly decreases with the increase of pressure, except for that corresponding to $M a_{2}=0.5$. The average $\varphi_{\mathrm{LBO}}$ at $M a_{2}=0.3$ is 0.36 , which is $9.3 \%, 19.3 \%$, and $31.0 \%$ smaller than that at $M a_{2}=0.4,0.5$, and 0.6 . The worst flame stability occurs at $0.06 \mathrm{MPa}$ and $M a_{2}=0.6$, and the maximum $\varphi_{\mathrm{LBO}}$ is 0.65 . As expected, the minimum $\varphi_{\mathrm{LBO}}$ was obtained to be 0.22 under the condition of $0.1 \mathrm{MPa}$ and $M a_{2}=0.3$, which is $44.5 \%$ less than that of $0.1 \mathrm{MPa}$ and $M a_{2}=0.6$. Additionally, the slope of $\varphi_{\mathrm{LBO}}$ decreasing with pressure is approximately 0.66 per $0.1 \mathrm{MPa}$ getting rid of the point corresponding to $M a_{2}=0.5$ and $P=0.01 \mathrm{MPa}$.
3.2. Discussion. The ignition and lean blowout, the coupling of energy, are complex processes, which can be analyzed by the nonreaction flow field [19, 35]. Previous studies have proved that the time-scale theory can well explain the flame stability of the cavity with dual-vortex $[10,19]$. Besides, the principle of flame stabilization by the primary and secondary vortexes in the cavity is also summarized by Prof. Zhao [7], which indicated that the fuel/air mixture must be ignited before the intersection of the primary and secondary vortexes, so that the high-temperature burned gas could be produced and refluxed to ignite the fresh mixture.

Figure 7 demonstrates the schematic of flame stability in trapped vortex in a $20 \mathrm{~mm}$ section far from the center section. It can be considered that the fuel/air mixture is fully mixed when it enters the trapped vortex zone with the AMI fuel supply device. A section $a-b$ with the profile of velocity $A$ $-A$ is randomly selected in the trapped vortex. There must exist a point $B$ that can stabilize the flame, where the airflow velocity is the same as the flame propagation velocity and the direction is opposite, denoted as

$$
V_{\mathrm{sf}}=V_{\mathrm{B}}
$$

where $V_{\text {sf }}$ is the flame propagation velocity and $V_{\mathrm{B}}$ is the airflow velocity of point $B$.

It is worth noting that the point $B$ will move downstream along the streamline of the tapped vortex to the critical point of flame stability as the $V_{\mathrm{f}}$ gradually increases. The critical point, namely the separation point of the primary and secondary vortices, is located at the boundary of the primary vortex and forms an angle of $\beta$ with the vortex core, an inlet of the fore-wall. Then, the lean blowout will occur if the $V_{\mathrm{f}}$ continues to increase.

Given that the trapped vortex zone is filled with almost completely burned, high temperature, and homogeneous combustible gas. Thus, the mass and energy exchange between fresh mixed gas and burned gas occurs in the shear layer of the trapped vortex. When the fresh mixture obtains enough energy before reaching the separation point of the trapped vortex to generate a stable flame, the primary vortex will burn stably; otherwise, a blowout will occur.

The flame stabilization process of the cavity is analyzed by the characteristic time-scale theory, which is widely accepted to understand the lean blowout in the recirculation zone [29]. The ignition delay time, $\tau_{c}$, including fuelair mixing time, $\tau_{\text {mix }}$, and ignition induction time, $\tau_{\mathrm{i}}$, are expressed as

$$
\tau_{\mathrm{c}}=\tau_{\text {mix }}+\tau_{\mathrm{i}}
$$

As mentioned above, the fuel entering the trapped vortex through the AMI can be considered as a fully mixed fuel-air mixture, and then

$$
\tau_{\text {mix }}<<\tau_{\mathrm{i}} \approx \tau_{\mathrm{c}}
$$




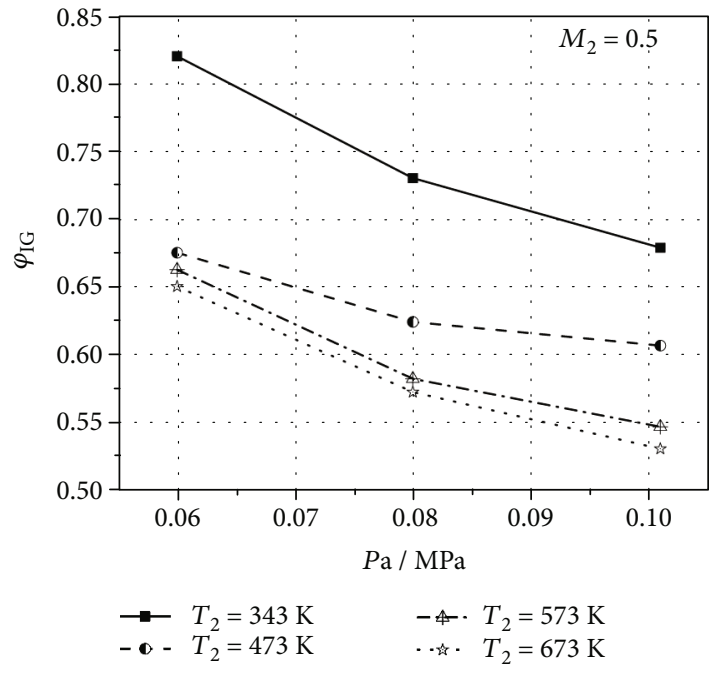

(a)

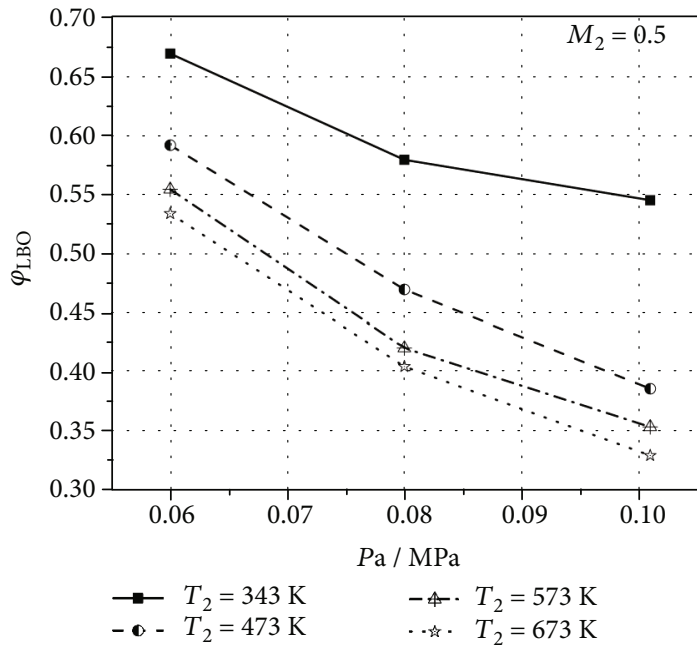

(b)

FIGURE 5: Lean ignition and lean blowout equivalence ratios of combustor with the various temperature at $M a_{2}=0.5$ : (a) lean ignition, (b) lean blowout.

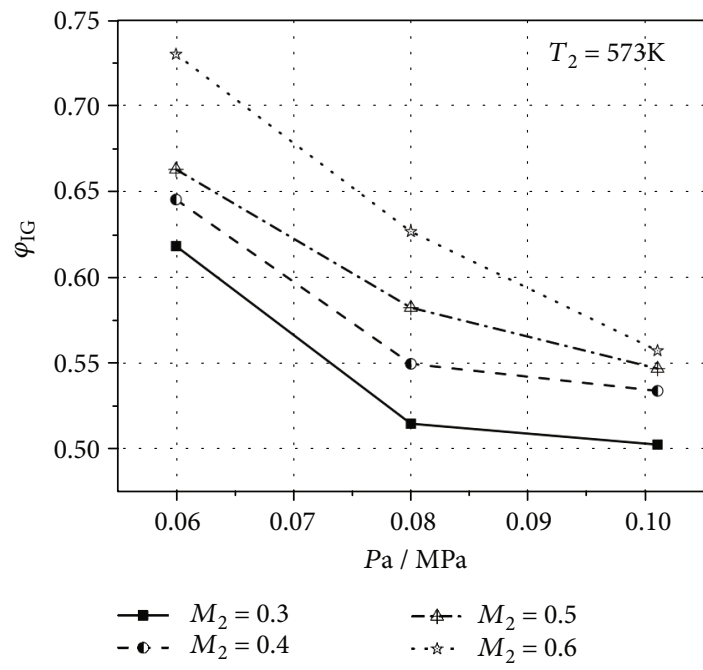

(a)

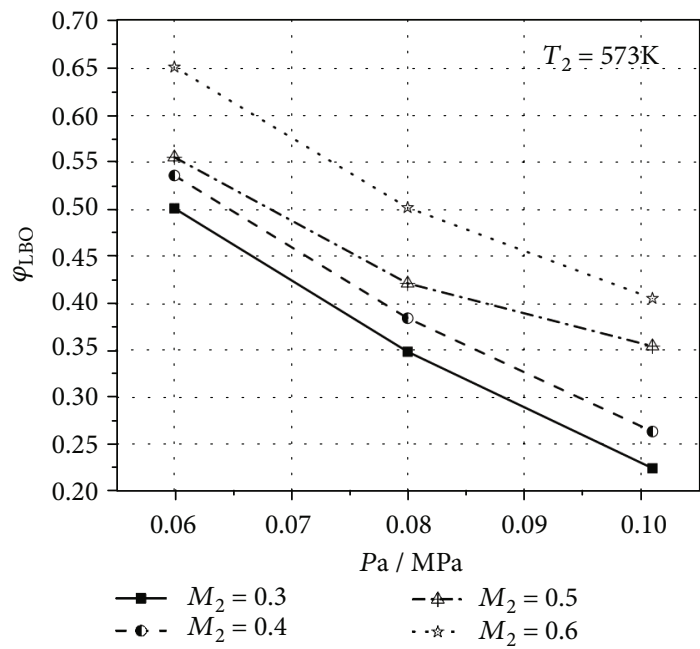

(b)

FIgURE 6: Lean ignition and lean blowout equivalence ratios of the combustor with various Mach numbers at $T_{2}=573 \mathrm{~K}$ : (a) lean ignition, (b) lean blowout.

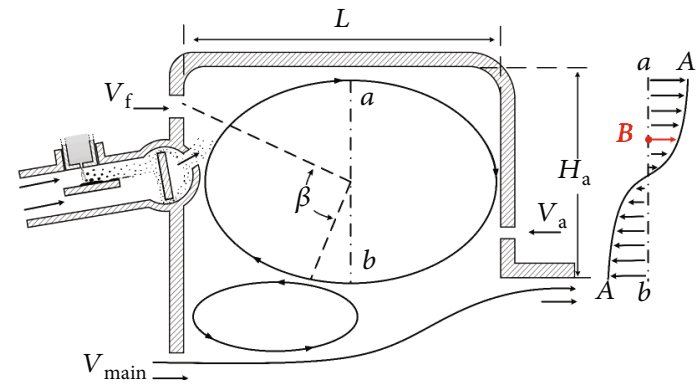

FIGURE 7: Schematic of flame stability in a trapped vortex.
According to Arrhenius [30],

$$
\tau_{c} \approx \tau_{\mathrm{i}} \propto \frac{1}{\varphi^{x} P^{v-1}} \exp \left(\frac{E}{R T}\right),
$$

where $x>0$ is constant and $v$ is the reaction series.

At the same time, given that the movement time of fresh mixture from entering the primary vortex to separation point is $\tau_{\mathrm{k}}$, that is

$$
\tau_{\mathrm{k}}=\frac{L_{\mathrm{v}}}{V_{\mathrm{c}}}
$$


where $L_{\mathrm{v}}$ is the distance of fresh mixture from entering the primary vortex to separation point and $V_{\mathrm{c}}$ is the average velocity of airflow in the primary vortex, where

$$
\begin{aligned}
L_{\mathrm{v}} & =\frac{180-\beta}{180} t\left(L+H_{b}\right), \\
V_{c} \approx \bar{V} & =\frac{2 \dot{m}}{B \cdot H_{b}} \cdot \frac{R T}{P},
\end{aligned}
$$

where $t$ is the elliptic coefficient, $L$ is the cavity length, $H_{\mathrm{b}}$ is the after the height of the cavity, $\dot{m}$ is the mass flow rate of cavity air, and $B$ is the cavity width, then Equation (6) can be expressed as

$$
\tau_{\mathrm{k}} \propto \frac{B \cdot H_{\mathrm{b}}\left(L+H_{\mathrm{b}}\right)}{2 \dot{m}_{\mathrm{c}}} \cdot \frac{P}{R T} .
$$

Thus,

$$
\tau_{\mathrm{k}} \propto \frac{L}{V_{\mathrm{c}}} \propto \frac{L}{M a_{\mathrm{in}}} .
$$

If $\tau_{\mathrm{c}}<\tau_{\mathrm{k}}$, then the fresh fuel-air mixture will be ignited continuously and form a stable flame, which can ignite the mainstream though the secondary vortex. Otherwise, the blowout will happen. At the critical state, that is defined as

$$
\tau_{\mathrm{c}}=\tau_{\mathrm{k}}
$$

According to Equations (5) and (10),

$$
\varphi \propto\left[\frac{M a}{L P^{v-1}} \exp \left(\frac{E}{R T}\right)\right]^{1 / x} .
$$

This indicates that given a cavity with the fully fuel-air mixture, the decreases in lean ignition and lean blowout equivalent ratios can be attributed by either the increase in cavity length, inlet pressure, and temperature or the decrease in Mach. In other words, Equation (11) is very consistent with the experimental results mentioned above.

\section{Conclusions}

A rectangular cavity pilot augmentor with a classical radial $\mathrm{V}$-gutter flameholder of the TBCC engine is designed with double inlets and outlets. The limits of lean ignition and lean blowout are obtained experimentally at several Mach numbers and inlet temperatures where the cavity length changes from $41.5 \mathrm{~mm}$ to $51.5 \mathrm{~mm}$ and inlet pressure varies from $0.06 \mathrm{MPa}$ to $0.10 \mathrm{MPa}$. Some valuable conclusions in the application are drawn as follows:

(i) The increase of the cavity length-height ratio in a proper range improves flame stability with an enlarged fuel/air mixture residence time. The average equivalence ratio of $\mathrm{LBO}$ in $L=51.5 \mathrm{~mm}$ at $M$ $a_{2}=0.3$ and $T_{2}=343 \mathrm{~K}$ is 0.725 , which is $2.60 \%$ and $8.13 \%$ larger than that in $L=46.5 \mathrm{~mm}$ and $L=41.5 \mathrm{~mm}$

(ii) A decreased tendency of lean ignition and lean blowout equivalence ratios is achieved at $T_{2}=343 \mathrm{~K}$, while the increased one is obtained at $T_{2}=573 \mathrm{~K}$, which is conducive to the evaporation of the fuel droplet

(iii) The increase in inlet pressure will lead to a linear decrease in the lean blowout equivalence ratio with a slope of 0.66 per $0.1 \mathrm{MPa}$, whereas the lean ignition equivalence has a rapid drop with the increase of pressure from $0.06 \mathrm{MPa}$ to $0.08 \mathrm{MPa}$ and reduces slowly with the growth of pressure in the range of $0.08 \mathrm{MPa}$ to $0.1 \mathrm{MPa}$

(iv) As an exception, the increase in the inlet Mach number and temperature will exaggerate the equivalence ratios of lean ignition and lean blowout

(v) The results reveal that the design of the cavity-based combustor can be predicted by the validated characteristic time-scale theory

\section{Data Availability}

The experimental data used to support the findings of this study are included within the article' in the Version 3.1.

\section{Conflicts of Interest}

The authors declare that they have no conflicts of interest.

\section{Acknowledgments}

This work was supported by the National Nature Science Foundation of China through the grant number 51506086. Also, Yakun Huang gratefully acknowledges the financial support from the China Scholarship Council.

\section{References}

[1] H. Miyagi, H. Kimura, J. Cabe, T. Powell, and R. Yanagi, "Combined cycle engine research in Japanese HYPR program," 34th AIAA/ASME/SAE/ASEE Joint Propulsion Conference and Exhibit, 1998.

[2] D. J. Bents, T. Mockler, J. Maldonado, J. L. Harp Jr., J. F. King, and P. C. Schmitz, "Propulsion system for very high altitude subsonic unmanned aircraft," NASA/TM-1998-206636, 1998.

[3] S. Bush and E. Gutmark, "Characterization of blowout limits for a V-gutter stabilized flame," in 34th AIAA/ASME/SAE/ASEE Joint Propulsion Conference and Exhibit, 1998.

[4] S. J. Shanbhogue, S. Husain, and T. Lieuwen, "Lean blowoff of bluff body stabilized flames: scaling and dynamics," Progress in Energy and Combustion Science, vol. 35, no. 1, pp. 98-120, 2009.

[5] P. C. Mancilla, P. Chakka, and S. Acharya, "Performance of a trapped vortex spray combustor," in ASME Turbo Expo, 2001.

[6] Y. Jin, X. He, B. Jiang, Z. Wu, G. Ding, and Z. Zhu, "Effect of cavity-injector/radial-strut relative position on performance 
of a trapped vortex combustor," Aerospace Science and Technology, vol. 32, no. 1, pp. 10-18, 2014.

[7] D. Zhao, E. Gutmark, and P. de Goey, "A review of cavitybased trapped vortex, ultra-compact, high-g, inter-turbine combustors," Progress in Energy and Combustion Science, vol. 66, pp. 42-82, 2018.

[8] L. J. Muzio and G. C. Quartucy, "Implementing NOx control: research to application," Progress in Energy and Combustion Science, vol. 23, no. 3, pp. 233-266, 1997.

[9] P. Logan, J. W. Lee, L. M. Lee, A. R. Karagozian, and O. I. Smith, "Acoustics of a low-speed dump combustor," Combustion and Flame, vol. 84, no. 1-2, pp. 93-109, 1991.

[10] W. M. Roquemore, D. Shouse, D. Burrus et al., "Trapped vortex combustor concept for gas turbine engines," in 39th AIAA aerospace sciences meeting \& exhibit, 2001.

[11] V. R. Katta and W. M. Roquemore, "Study on trapped-vortex combustor effect of injection on flow dynamics," Journal of Propulsion and Power, vol. 14, no. 3, pp. 273-281, 1998.

[12] W. A. Mair, "The effect of a rear-mounted disc on the drag of a blunt-based body of revolution," Aeronautical Quarterly, vol. 16, no. 4, pp. 350-360, 1965.

[13] V. R. Katta and W. M. Roquemore, "Numerical studies on trapped vortex concepts for stable combustion," Journal of Engineering for Gas Turbines and Power, vol. 120, no. 1, pp. 60-68, 1998.

[14] J. Bucher, R. G. Edmonds, R. C. Steele, D. W. Kendrick, B. C. Chenevert, and P. C. Malte, "The development of a lean premixed trapped vortex combustor," in ASME Turbo Expo, 2003.

[15] Y. Jin, H. Xiaomin, B. Jiang, W. Zejun, and G. Ding, "Design and performance of an improved trapped vortex combustor," Chinese Journal of Aeronautics, vol. 25, no. 6, pp. 864-870, 2012.

[16] F. Xing, P. Wang, S. Zhang et al., "Experiment and simulation study on lean blow-out of trapped vortex combustor with various aspect ratios," Aerospace Science and Technology, vol. 18, no. 1, pp. 48-55, 2012.

[17] Y. Jin, Y. Li, X. He et al., "Experimental investigations on flow field and combustion characteristics of a model trapped vortex combustor," Applied Energy, vol. 134, pp. 257-269, 2014.

[18] X. He, J. Zhang, J. Xu, J. Su, and M. Weri, "An experimental research of the performance of a trapped-vortex combustor," in 44th AIAA/ASME/SAE/ASEE joint propulsion conference \& exhibit, 2008.

[19] S. Chen, R. S. M. Chue, S. C. M. Yu, and J. U. Schlüter, "Spinning effects on a trapped vortex combustor," Journal of Propulsion and Power, vol. 32, no. 5, pp. 1133-1145, 2016.

[20] C. Merlin, P. Domingo, and L. Vervisch, "Immersed boundaries in large eddy simulation of compressible flows," Flow, Turbulence and Combustion, vol. 90, no. 1, pp. 29-68, 2013.

[21] Z. Wu, X. He, Y. Jin, Y. Song, and Y. Zhu, "Impact of interaction between cavity flow and mainstream on the performance of a model trapped vortex combustor," Proceedings of the Institution of Mechanical Engineers, Part G: Journal of Aerospace Engineering, vol. 230, no. 7, pp. 1181-1200, 2016.

[22] Z. Wu, X. He, B. Jiang, and Y. Jin, "Experimental investigation on a single-cavity trapped vortex combustor," International Communications in Heat and Mass Transfer, vol. 68, pp. 813, 2015.

[23] T. R. Meyer, M. S. Brown, L. P. Goss et al., "Optical diagnostics and numerical characterization of a trapped-vortex combus- tor," 38th AIAA/ASME/SAE/ASEE Joint Propulsion Conference \& Exhibit, 2002.

[24] Y. Jin, X. He, J. Zhang, B. Jiang, and Z. Wu, "Numerical investigation on flow structures of a laboratory-scale trapped vortex combustor," Applied Thermal Engineering, vol. 66, no. 1-2, pp. 318-327, 2014.

[25] K. K. Agarwal, S. Krishna, and R. V. Ravikrishna, "Mixing enhancement in a compact trapped vortex combustor," Combustion Science and Technology, vol. 185, no. 3, pp. 363-378, 2013.

[26] Y. Deng and F. Su, "Low emissions trapped vortex combustor," Aircraft Engineering and Aerospace Technology, vol. 88, no. 1, pp. 33-41, 2016.

[27] Z. Zhu, X. He, C. Xue, L. Hong, Y. Zhu, and Y. Song, “Experimental investigations on combustion characteristics of a cavity pilot augmentor of the turbine-based combined cycle engine," Journal of Aerospace Engineering, vol. 229, no. 11, pp. 2024-2034, 2015.

[28] M. Li, X. He, Y. Zhao, Y. Jin, Z. Ge, and Y. Sun, "Dome structure effects on combustion performance of a trapped vortex combustor," Applied Energy, vol. 208, pp. 72-82, 2017.

[29] G. C. Williams, H. C. Hottel, and A. C. Scurlock, "Flame stabilization and propagation in high velocity gas streams," Symposium on Combustion and Flame, and Explosion Phenomena, vol. 3, no. 1, pp. 21-40, 1948.

[30] F. Vogel, K. A. Smith, J. W. Tester, and W. A. Peters, "Engineering kinetics for hydrothermal oxidation of hazardous organic substances," AICHE Journal, vol. 48, no. 8, pp. 18271839, 2002. 